\title{
Advanced techniques in magnetic resonance imaging of the brain in children with ADHD
}

\author{
Giuseppe Pastura1, Paulo Mattos², Emerson Leandro Gasparetto³, \\ Alexandra Prufer de Queiroz Campos Araújo ${ }^{4}$
}

\begin{abstract}
Attention deficit hyperactivity disorder (ADHD) affects about $5 \%$ of school-aged child. Previous published works using different techniques of magnetic resonance imaging (MRI) have demonstrated that there may be some differences between the brain of people with and without this condition. This review aims at providing neurologists, pediatricians and psychiatrists an update on the differences between the brain of children with and without ADHD using advanced techniques of magnetic resonance imaging such as diffusion tensor imaging, brain volumetry and cortical thickness, spectroscopy and functional MRI. Data was obtained by a comprehensive, non-systematic review of medical literature. The regions with a greater number of abnormalities are splenium of the corpus callosum, cingulated girus, caudate nucleus, cerebellum, striatum, frontal and temporal cortices. The brain regions where abnormalities are observed in studies of diffusion tensor, volumetry, spectroscopy and cortical thickness are the same involved in neurobiological theories of ADHD coming from studies with functional magnetic resonance imaging.

Key words: attention deficit disorder with hyperactivity, magnetic resonance imaging, diffusion tensor imaging, cerebral cortex, magnetic resonance spectroscopy, functional MRI.
\end{abstract}

Técnicas avançadas de ressonância magnética do crânio em crianças portadoras de TDAH

\section{RESUMO}

O transtorno do déficit de atenção e hiperatividade (TDAH) afeta cerca de 5\% das crianças em idade escolar. Diversos trabalhos publicados utilizando diferentes técnicas de ressonância magnética mostram que pode haver diferenças entre o cérebro de portadores e não-portadores deste transtorno. Esta revisão visa fornecer aos neurologistas, pediatras e psiquiatras uma atualização sobre diferenças entre o cérebro de portadores e nãoportadores deste transtorno, utilizando técnicas avançadas de ressonância magnética, como imagem pelo tensor da difusão, volumetria e espessura cortical, espectroscopia e ressonância magnética funcional. Os dados foram obtidos pela revisão abrangente nãosistemática da literatura médica. As regiões com maior número de anormalidades são: esplênio do corpo caloso, giro do cíngulo, núcleo caudado, cerebelo, estriado, córtex frontal e temporal. As regiões do cérebro onde as anormalidades são observadas em estudos de tensor de difusão, volumetria, espectroscopia e espessura cortical são as mesmas envolvidas nas teorias neurobiológicas do TDAH provenientes de estudos com ressonância magnética funcional.

\section{Correspondence \\ Giuseppe Pastura \\ Av. Bruno Lobo, 50 \\ 21941-612 Rio de Janeiro RJ - Brasil \\ E-mail: giuseppe.pastura@terra.com.br}

Received 16 July 2010

Received in final form 23 September 2010

Accepted 30 September 2010
Palavras-chave: transtorno do déficit de atenção com hiperatividade, imagem por ressonância magnética, imagem de tensor de difusão, córtex cerebral; espectroscopia de ressonância magnética, ressonância magnética funcional.

Departamento de Pediatria do Instituto de Puericultura e Pediatria Martagão Gesteira da Universidade Federal do Rio de Janeiro (UFRJ), Rio de Janeiro RJ, Brazil: 'MD, MSc, Professor Assistente de Pediatria, UFRJ; ${ }^{1} \mathrm{MD}$, PhD, Professor Adjunto de Psiquiatria, UFRJ: ${ }^{3} \mathrm{MD}$, PhD, Professor Adjunto de Radiologia, UFRJ; ${ }^{4} \mathrm{MD}$, PhD, Professora Adjunta de Neuropediatria, UFRJ. 


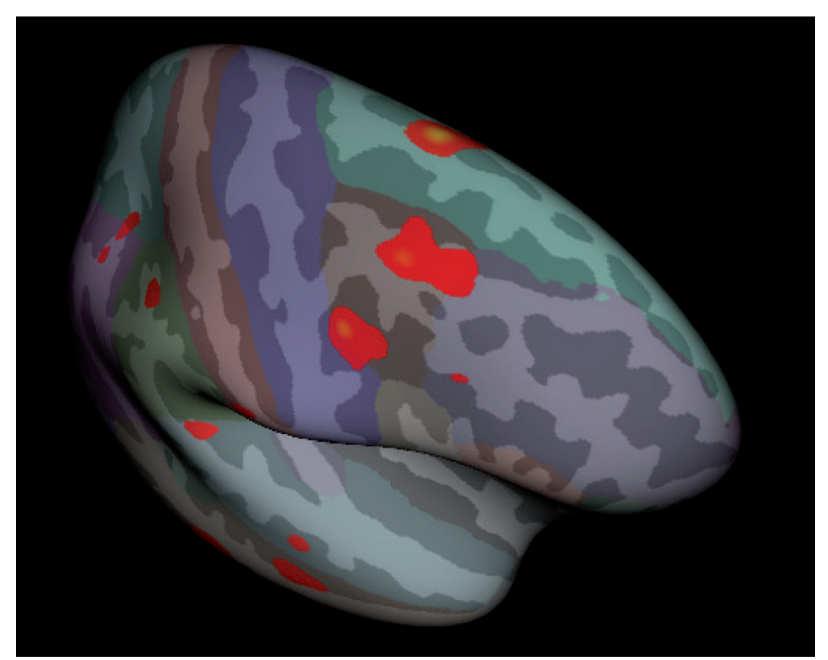

Fig 1. Lateral view of the inflated right cerebral hemisphere showing areas of reduced cortical thickness in prefrontal region (Source: unpublished data from a comparative analysis of 17 ADHD patients and 17 controls matched for age and sex).

Attention deficit hyperactivity disorder (ADHD) consists of a pattern of inattention and/or hyperactivity, more frequent than that commonly found in children of similar level of development and is associated with functional impairment. The diagnosis of this disorder can be established using the criteria of the American Psychiatric Association ${ }^{1}$, and the cardinal symptoms can not be better explained by the presence of another psychiatric condition, such as humor or personality disorder, among others. According Polanczyk et al. ${ }^{2}$, the prevalence of ADHD is around 5\% of school-age children, although the prevalence may vary according to the diagnostic criteria used and the type of sample.

Studies using different techniques of magnetic resonance imaging (MRI) scan of the brain show morphological and functional differences between the brains of ADHD patients and controls, which may be useful in understanding the neurobiology of the disorder ${ }^{3,4}$. Among all the techniques of MRI in this study, we explore those most used in clinical studies: diffusion tensor imaging, brain morphometry, spectroscopy and functional MRI.

A summary of the main findings of each technique in ADHD patients can be seen in Tables 1-4 and examples of the main techniques described in this work can be seen in Figures 1-3.

\section{Diffusion tensor imaging}

Diffusion tensor MR imaging (DTI) opened a new era in the field of neuroimaging as it allowed, on a non-invasive and individual basis, the display of the anatomical connections between different cerebral areas, bringing

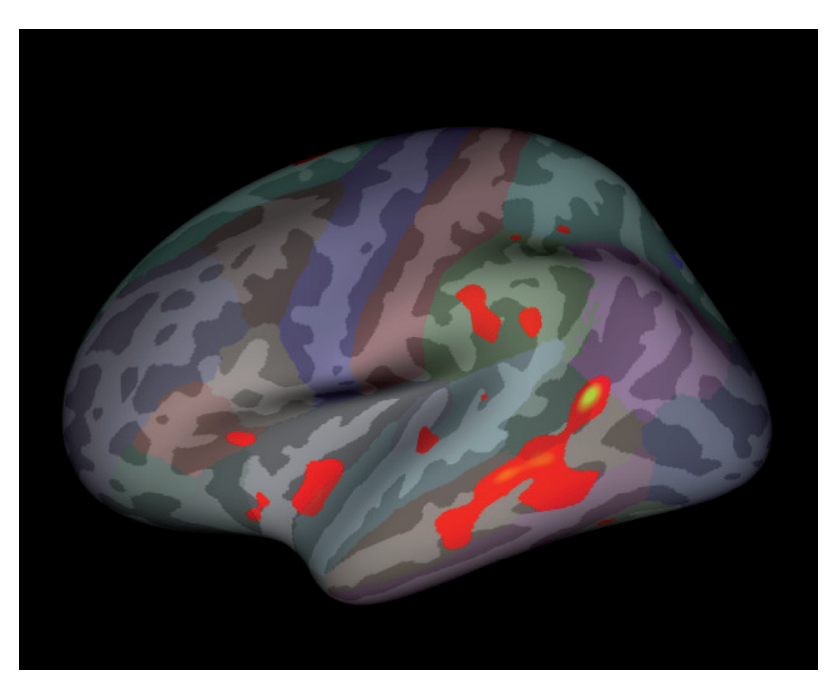

Fig 2. Lateral view of the inflated left cerebral hemisphere showing areas of reduced cortical thickness predominantly in the temporal region (Source: unpublished data from a comparative analysis of 17 ADHD patients and 17 controls matched for age and sex).

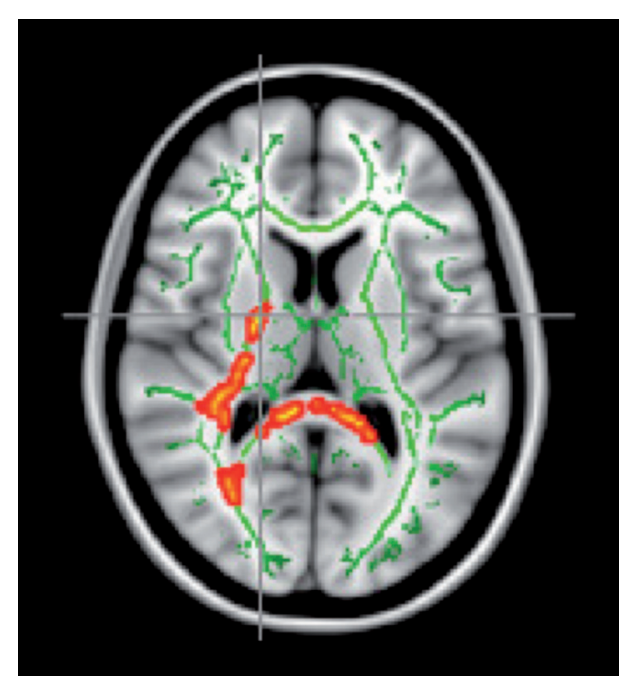

Fig 3. Statistical results of the DTI through TBSS technique showing areas of reduced fractional anisotropy in the splenium of the corpus callosum and posterior leg of the right internal capsule (Source: unpublished data from a comparative analysis of 17 ADHD patients and 17 controls matched for age and sex).

advantages in the functional study of the brain ${ }^{5}$. DTI is sensitive to changes in the structure of the cerebral white matter, providing relevant information concerning its integrity and connectivity ${ }^{6,7}$.

DTI is also sensitive to the direction and extent of water diffusion in the brain, which can be quantified by two key measures: the mean diffusivity (MD) and fractional anisotropy (FA). According to Silk et al. ${ }^{7}$, the first represents the magnitude of water diffusion in any direction within the voxel and can be measured in $\mathrm{mm}^{2} / \mathrm{sec}$. FA provides information about the direction of water dif- 
Table 1. Summary of ADHD findings in DTI studies.

\begin{tabular}{lccl}
\hline Author & Publication year & Study design & ADHD findings \\
\hline Ashtari et al. ${ }^{4}$ & 2005 & Cross-sectional & $\begin{array}{l}\text { Reduction of FA in the right supplementary motor area, right anterior } \\
\text { internal capsule, right cerebral peduncle, left middle cerebellar } \\
\text { peduncle and left cerebellum. }\end{array}$ \\
Hamilton e cols. ${ }^{57}$ & 2008 & Cross-sectional & $\begin{array}{l}\text { Reduced FA in both cortico-spinal tracts and the superior longitudinal } \\
\text { fasciculus bilaterally. }\end{array}$ \\
Pavuluri et al. ${ }^{9}$ & 2009 & Cross-sectional & $\begin{array}{l}\text { Reduced FA in corona radiata. } \\
\text { Silk et al. }{ }^{7}\end{array}$ \\
2009 & Cross-sectional & $\begin{array}{l}\text { Increased anisotropy in prefrontal regions and left hemisphere } \\
\text { temporal and parietal-occipital right hemisphere. } \\
\text { Increased FA in the caudate in patients and controls, but with different } \\
\text { trajectories. }\end{array}$ \\
\hline
\end{tabular}

Table 2. Summary of ADHD findings in morphometric studies.

\begin{tabular}{|c|c|c|c|}
\hline Author & Publication year & Study design & ADHD findings \\
\hline Hynd et al. ${ }^{22}$ & 1993 & Cross-sectional & $\begin{array}{l}\text { Asymmetry of the caudate nuclei, with a greater area to the right, } \\
\text { which is the result of reduction of area of the left caudate. }\end{array}$ \\
\hline $\begin{array}{l}\text { Semrud- } \\
\text { Clikeman et al. }{ }^{16}\end{array}$ & 1994 & Cross-sectional & Reduced area of posterior corpus callosum, especially the splenium. \\
\hline Giedd et al. ${ }^{20}$ & 1994 & Cross-sectional & Reduced area in the region of the rostrum of the corpus callosum. \\
\hline Filipek et al. ${ }^{27}$ & 1997 & Cross-sectional & $\begin{array}{l}\text { Volumetric reduction in left caudate nucleus with reversal of asym- } \\
\text { metry observed in controls, in the frontal region anterosuperior right } \\
\text { white right anterolateral bilateral inferior and white retro-calosal } \\
\text { bilateral. }\end{array}$ \\
\hline Mataro et al. ${ }^{21}$ & 1997 & Cross-sectional & Increase in area of the caudate nucleus. \\
\hline Castellanos et al. ${ }^{3}$ & 2002 & Prospective & $\begin{array}{l}\text { Reduction of total brain volume and cerebellar. Volumetric abnor- } \\
\text { malities persisted with the growth, except in the caudate nucleus. }\end{array}$ \\
\hline Abernethy et al. ${ }^{26}$ & 2002 & Cross-sectional & Volume reduction of the right caudate nucleus and left hippocampus. \\
\hline Carmona et al. ${ }^{25}$ & 2005 & Cross-sectional & Overall reduction in brain volume of $5.4 \%$. \\
\hline Valera et al. ${ }^{17}$ & 2007 & Meta-analysis & $\begin{array}{l}\text { Reduction of cerebellar volume; splenium of the corpus callosum, } \\
\text { total brain volume and right hemisphere, and right caudate. }\end{array}$ \\
\hline Mackie et al. ${ }^{30}$ & 2007 & Prospective & $\begin{array}{l}\text { Non-progressive reduction in the volume of the superior cerebellar } \\
\text { vermis. Patients with poorer prognosis present progressive reduction } \\
\text { of the volume in posterior inferior cerebellar region bilaterally. }\end{array}$ \\
\hline Shaw et al. ${ }^{36}$ & 2007 & Prospective & $\begin{array}{l}\text { Delay in cortical development observed through measurement of } \\
\text { cortical thickness. }\end{array}$ \\
\hline Makris et al. ${ }^{37}$ & 2007 & Cross-sectional & $\begin{array}{l}\text { Reduced cortical thickness in areas related to attentional circuits: right } \\
\text { inferior parietal lobe, prefrontal cortex and bilateral anterior cingulate } \\
\text { gyrus bilaterally. }\end{array}$ \\
\hline
\end{tabular}

fusion in each voxel and its range varies from 0 to 1 , zero being the value on the isotropic diffusion (when there is no predominance of one direction of diffusion on the other). In gray matter, the diffusion of water is equal in all directions, tending to isotropy. On the other hand, the diffusion in the white matter is highly anisotropic and occurs easier in the same direction of the tracts ${ }^{6}$.
In this region, the FA values are high, since the diffusion of water occurs along myelinated fibers. Increases in normal values of FA may represent either an increase in density of myelinated fibers or a reduction in neural connections. The relationship between microstructure and anisotropy is multifactorial. The integrity of the myelin sheath and axonal membranes cause restriction of 
Table 3. Summary of ADHD findings in spectroscopy studies.

\begin{tabular}{lcll}
\hline Author & Publication year & Study design & ADHD findings \\
\hline MacMaster et al. ${ }^{45}$ & 2003 & Cross-sectional & $\begin{array}{l}\text { Increased levels of glutamate and glutamine in frontostriatal circuits. } \\
\text { Sun et al. }{ }^{46}\end{array}$ \\
2005 & Cross-sectional & $\begin{array}{l}\text { Reduction of NAA/Cr ratio bilaterally in the lenticular nuclei in patients } \\
\text { with ADHD combined subtype, but no difference was observed } \\
\text { among patients with ADHD inattentive subtype and the control } \\
\text { group. }\end{array}$ \\
& 2007 & Cross-sectional & $\begin{array}{l}\text { Lower levels of relationship Glu/Cr in the anterior cingulate cortex. } \\
\text { Perlov et al. }{ }^{42}\end{array}$ \\
Fayed et al. ${ }^{44}$ & 2007 & Cross-sectional & $\begin{array}{l}\text { Increase in the ratio NAA/Cr in the right prefrontal regions and the } \\
\text { left semi- oval center. }\end{array}$ \\
Ehlis et al. ${ }^{48}$ & 2008 & Cross-sectional & $\begin{array}{l}\text { Lower oxygen uptake in ventro-lateral prefrontal cortex during the } \\
\text { execution of working memory tests. }\end{array}$ \\
\hline
\end{tabular}

Table 4. Summary of ADHD findings in fRM studies.

\begin{tabular}{|c|c|c|c|}
\hline Author & Publication year & Study design & ADHD findings \\
\hline Vaidya et al. ${ }^{58}$ & 1998 & Cross-sectional & Change of fronto-striatal activation. \\
\hline Rubia et al. ${ }^{24}$ & 1999 & Cross-sectional & $\begin{array}{l}\text { Lower response in the medial prefrontal cortex right in the prefrontal } \\
\text { cortex, right inferior frontal and left caudate nucleus. }\end{array}$ \\
\hline Durston et al..$^{55}$ & 2003 & Cross-sectional & $\begin{array}{l}\text { Change in the pattern of activation of fronto-striatal when compared } \\
\text { to children of the same level of development without ADHD. }\end{array}$ \\
\hline Tamm et al. ${ }^{56}$ & 2004 & Cross-sectional & $\begin{array}{l}\text { Abnormalities in brain activation during motor response inhibition, } \\
\text { including low activation of anterior cingulate and middle extending } \\
\text { to the supplementary motor area. Hyper-activation of the left tem- } \\
\text { poral gyrus. }\end{array}$ \\
\hline Rubia et al. ${ }^{51}$ & 2005 & Cross-sectional & $\begin{array}{l}\text { Minor brain activity, especially in the mesial frontal cortex of the right } \\
\text { hemisphere during both tests and in the prefrontal cortex and the } \\
\text { right lower left caudate during the inhibition test. }\end{array}$ \\
\hline Rubia et al. ${ }^{54}$ & 2009 & Cross-sectional & $\begin{array}{l}\text { Reduction of activation in fronto-striatal network-parieto-cerebellar } \\
\text { bilaterally during tests of attention. Increased activation in the } \\
\text { orbitofrontal cortex and superior temporal, reward-related. }\end{array}$ \\
\hline Casey et al. ${ }^{59}$ & 2007 & Cross-sectional & $\begin{array}{l}\text { Correlation between a lower fractional anisotropy in the fronto-striatal } \\
\text { regions (prefrontal cortex and caudate nucleus) and poorer cognitive } \\
\text { performance on tests of inhibition. }\end{array}$ \\
\hline
\end{tabular}

diffusion orthogonal to fibers, while an intact intra-axonal structure is directly correlated with the diffusion parallel to fiber ${ }^{6}$.

Based on the principles outlined above, the DTI technique makes it possible to examine the nature and extent of neuronal dysfunction associated with ADHD which could not be identified by conventional $\mathrm{MRI}^{7,8}$. Using a specific method of analysis for studies with DTI named tract-based spatial statistics (TBSS $)^{9}$, Silk et al. ${ }^{7}$ examined the micro-structure of the cerebral white matter of individuals with ADHD and controls. The TBSS enables an analysis restricted to the center of the largest tracts of white matter rather than examining the brain as a whole. In this study, it was observed an increase in
FA in prefrontal regions and left hemisphere temporal and parietal-occipital right hemisphere of patients with ADHD. The explanation for this change is based on the fact that the smaller the neuronal branches, the lower the magnitude of diffusion along directions of secondary and higher values observed for the FA. Thus, these increased values of FA could mean a reduction in normal branching in neuronal pathways connecting fronto-temporal and occipito-parietal. There was also an increase in FA with age in both groups of cases as in controls, which is supported by previous studies ${ }^{10}$.

According to El-Sayed et al. ${ }^{11}$, ADHD represents a maturational deficit that can be corrected with time. The results of the study of Silk et al. ${ }^{7}$ partly corroborate this 
theory in that we observe an increase of FA over time in both the brains of ADHD patients as in controls. However, the regions in which we observe an increase in localized FA in patients with ADHD is contrary to this theory.

In a cross-sectional study comparing 18 patients with ADHD inattentive subtype and 15 healthy subjects aged between 7 and 11 years, Ashtari et al. ${ }^{4}$ observed reduction in FA in right supplementary motor area, right anterior internal capsule, right cerebral peduncle, left middle cerebellar peduncle and left cerebellum in the ADHD group. This reduction in FA is interesting because it affects the supplementary motor area, an area known to be related to planning, initiation and execution of motor $\operatorname{acts}^{12}$. The findings of reduced FA in the left cerebellum are consistent with other studies that had shown anatomical abnormalities in the cerebellum ${ }^{3}$ and clinical studies involving patients with cerebellar lesion ${ }^{13}$. In the latter, patients showed deficits in executive functions, including planning, sequencing, visual-spatial functions, language, verbal memory and modulation of affection. A limitation to this study is the small sample size and the fact that more than $60 \%$ of patients used medication during the image acquisition.

Silk et al. ${ }^{14}$ investigated specifically the basal ganglia, an important part of the fronto-striatal network, implicated in the neurobiology of ADHD. Analyzing 15 males between 8 and 18 years, ADHD patients and controls, they observed an increase in FA in the brain as a whole, age-dependent in both groups. However, the increase in FA in caudate followed different paths in the two groups, representing a delay in brain development of ADHD patients.

In a recent study involving the use of DTI in patients with ADHD and bipolar disorder, Pavuluri et al. ${ }^{15}$ observed that individuals with ADHD have reduced FA in the anterior corona radiata, a region that makes the association between the brainstem and neocortex, and may contribute to the fronto-striatal dysfunction observed in both ADHD patients and in patients with bipolar disorder.

\section{Brain morphometry}

Through the evaluation of brain morphometry, it is possible to evaluate the longitudinal development of white and gray matter, and to study many neurological and psychiatric diseases. Brain morphometry can be accessed by measuring the area of certain structures, the volume of gray and white matter separately (covering each hemisphere) or as a whole ${ }^{3,16}$.

Imaging studies assessing brain morphometry in patients with ADHD do not always have converging results ${ }^{17}$. Baumeister and Hawkins ${ }^{18}$ question the consis- tency of imaging studies in ADHD patients suggesting a publication bias given the predominance of studies reporting differences between cases and non-ADHD patients. According to these authors, there is a devaluation of results that fail to demonstrate differences between these groups of individuals. Moreover, the authors question the causal link between abnormalities in imaging studies and ADHD. This is because there are studies showing that the behavioral abnormalities of a particular psychiatric disorder, such as ADHD, may lead to the emergence of changes in brain structure or function, which has been shown in patients with schizophrenia and depression ${ }^{19}$.

An example of this point discussed above is the work of Semrud-Clikeman et al. ${ }^{16}$, showing a smaller area in the splenium of the corpus callosum in patients with ADHD, which was not observed by Giedd et al. ${ }^{20}$, who observed reduction of the rostrum, and the studies of Mataró et al. ${ }^{21}$ and Hynd et al. ${ }^{22}$, who found discordant data on the size of the caudate of patients with ADHD. According to Seidman et al. ${ }^{23}$, there are several causes for the low concordance between the imaging studies in ADHD: influence of the use or not of medication during the acquisition of images; presence of comorbidities; variation in sex ratio in different studies; the presence or absence of family history of ADHD and perinatal complications; and, finally, the inherent variations of the different subtypes of ADHD. Despite these confounding factors, the majority of neuroimaging studies are concordant for the presence of volume reduction in dorsolateral prefrontal cortex, caudate, globus pallidus, corpus callosum and cerebellum. These results show a vast network of abnormalities distributed throughout the brain of patients with ADHD.

In order to clarify which brain regions exhibit the most consistent structural differences, Valera et al. ${ }^{17}$ conducted a meta-analysis with structural neuroimaging data in patients with ADHD. Meta-analysis are very useful in that they are capable of amplifying individual results of small samples by combining the studies. In this study, regions that showed statistically significant differences between ADHD patients and controls were: cerebellum; splenium of the corpus callosum, total brain volume and right hemisphere, and right caudate. The authors also mention, as a major cause for seemingly contradictory findings in previous studies, the great variations in how certain regions, such as the frontal region and the corpus callosum, are divided to study.

In order to determine the effect of prior exposure to stimulants in anatomical abnormalities in patients with ADHD and to examine the longitudinal trajectory of brain growth in ADHD patients and normal individuals, Castellanos et al. ${ }^{3}$ conducted the evaluation study 
of 152 ADHD patients of both sexes and 139 controls in a period of ten years. Each patient underwent at least four MRI scans. Of patients with ADHD, 49 patients underwent imaging before initiating the use of stimulant medication.

Naïve-drug ADHD individuals did not show any difference from patients receiving treatment in any parameter examined in gray matter or in caudate nucleus or cerebellum. However, ADHD naïve-drug individuals showed less volume of white matter compared to controls and medicated patients. Non-medicated patients had lower cerebellar volume, temporal gray matter and total brain volume compared with controls. Treated patients did not differ from controls on any measure of white matter. Interestingly, within the group of patients, the lower the volume of gray matter of the frontal and temporal region, the caudate and the cerebellum, the greater the severity of symptoms. The curves of brain development were significantly higher in controls than in the group of cases for total brain volume and for all other brain measures. There was no difference in curve shape between patients and controls except for the caudate. This difference in shape represents a normalization of the volume of this structure during adolescence in patients with ADHD, which may explain the fact that the symptoms of impulsivity improve after 10 years of age. Moreover, the difference in cerebellar volume curve persists all the time.

In apparent opposition to other studies such as Rubia et $\mathrm{al}^{24}$, the findings of Castellanos et al. ${ }^{3}$ are not compatible with the hypothesis of a primarily frontal abnormality as the neurobiological basis of ADHD. In this study, ADHD was associated with a reduction of about $3 \%$ of brain volume, being more marked in the white matter in untreated patients. As the growth curves for ADHD patients and controls are essentially parallel, it is suggested that the process of brain development in childhood and adolescence appears to be preserved and that the symptoms reflect a fixed and previously started neurobiological insult.

Carmona et al. ${ }^{25}$ compared the brain morphometry of 25 cases and 25 controls for differences in global and regional gray and white matter. It was observed that there is a difference of $5.4 \%$ between the brain volume of patients and non-ADHD individuals, mainly due to reduced volume of gray matter in patients with ADHD. The findings of gray matter could be summarized as follows: motor circuit including the cerebellum, peri-rolandic area and rolandic operculum, orbitofrontal cluster, anterior cingulate, left middle and posterior, and temporal lobe. The authors suggested that the abnormalities observed in the first group are consistent with theories on the neurobiology of ADHD involving cortico-subcor- tical dysfunction and loss of inhibitory control. The abnormalities found in the orbitofrontal area, especially on the right, are known to be related to impulsive behavior in adults with ADHD and the changes of the cingulum are relevant because this region belongs to the midline attention system. Finally, the volume reduction observed in the right temporal gyrus has been described in ADHD children with a history of low birth weight ${ }^{26}$. In this study no differences were detected in the volume of white matter or cerebrospinal fluid of patients with ADHD, unlike other studies ${ }^{27}$.

Mostofsky et al. ${ }^{28}$ observed that ADHD patients had smaller volumes of frontal lobe and this difference was not seen in other lobes. In the frontal lobe, there was a reduction in both the gray and white matter, with some kind of laterality in this loss: the white matter loss was more prominent in the left frontal region, while gray matter loss occurred bilaterally, but predominantly on the right. These findings suggest a different contribution of left and right hemispheres. The abnormalities are bilateral in gray matter, especially on the right, representing anomalies of neuronal structure, while the white matter abnormalities (lateralized to the left) reflect the interruption of afferent and efferent connections of the frontal lobe.

There is growing interest in the role of the cerebellum in the pathogenesis of ADHD. Reductions in the total volume of the cerebellum and vermis have been reported frequently in patients with $\mathrm{ADHD}^{3}$. More advanced techniques such as DTI have also shown the relationship between reduction of FA in the cerebellum and reduced attention ${ }^{4}$. The old concept that the cerebellum is a region involved only with motor control has been weakened, since several studies have demonstrated the role of this structure in the executive functions in general and in attention in particular ${ }^{29}$. In a longitudinal study on the development of the cerebellum in 36 patients with $\mathrm{ADHD}$ and same number of healthy individuals, Mackie et al. ${ }^{30}$ observed a highly specific abnormality: reduced volume in the superior vermis. This finding had never been described in previous studies that used measures of the cerebellum as a whole. In this study, comparison was held between the trajectory of cerebellar development in ADHD patients with good and poor outcome. The results showed that the subjects with good outcome showed a growth below the control group, but parallel to it. Moreover, the group with poor outcome showed a progressive reduction of total cerebellar volume, loosing the normal trajectory during adolescence. These findings are consistent both with the hypothesis of progressive neuroanatomical deficits and the hypothesis of fixed deficits of ADHD.

In recent years, a MRI technique for studying the 
brain targeting the cortical thickness was developed and facilitates the visualization of cortical activation patterns, especially the detailed topographical organization of the cortex $^{31}$. In a recent study of the evolution of cortical thickness and volume of white matter in adolescents and young adults, Tamnes et al. ${ }^{32}$ demonstrated a reduction of cortical thickness and an age-dependent increase in the volume of white matter. In most brain regions, cortical thickness was reduced on a non-linear way, mainly in adolescence. The greatest loss of cortical thickness occurred in the parietal lobe followed by the frontal lobe, cingulate gyrus and occipital lobe. According to the authors, the loss of cortical thickness could be explained by reducing the number of synapses associated with reductions in neuropil and glial cells. Unlike study of Shaw et $\mathrm{al}^{33}$, there was no increase in gray matter at any time, possibly due to age differences of the samples, and there was also a linear increase in the volume of white matter.

Thus, the results of Ostby et al. ${ }^{34}$ confirm the general notion that gray and white matter reduce their volume and the lateral ventricles increase theirs from late childhood to adolescence. However, volumetric reductions were not observed in all structures of gray matter, since there was no effect of age on the volume of the hippocampus and on the other hand, the tonsils showed increased volume. The cortex volume reduction was due to both reduced thickness and by reducing the covered area. The white matter volume changed more markedly than the cortical and subcortical gray matter. All volumes of white matter analyzed showed a non-linear and decelerating increase over time. Myelination constitutes the main element of brain development during late childhood and adolescence. Nucleus accumbens and basal ganglia changed little over time compared to the gray and white matter. As to the cerebellum, there was a trend towards increased overall volume with reduced volume of gray matter in a linear fashion. According to the authors, the reduction of gray matter reflects in part the process of loss (pruning) of synapses and partly the increase in myelination in the interface with the white matter ${ }^{33}$.

There are studies showing that brain activity at rest and in response to neuropsychological tests is similar between ADHD patients and younger controls, a theory that reinforces the hypothesis of a maturational deficit in cortical development as the neurobiological basis of $\mathrm{ADHD}^{11,24}$. However, other studies demonstrate a distinct neurobiology in patients with ADHD and are compatible with ADHD representing a deviation from normal brain development ${ }^{35}$.

In order to explore these issues, in 2007, Shaw et al. ${ }^{36}$ published a study aimed at defining the trajectory of cortical development in ADHD patients by the measurement of cortical thickness. It was observed that, al- though the developmental pattern is similar between cases and controls, there is marked difference in time between both. It was observed that the group with ADHD reached the peak of cortical thickness with a median of 10.5 years, while the control group did so with a median of 7.5 years. These differences were more prominent in the median prefrontal cortex, where the group of patients with ADHD reached peak of cortical thickness five years after the controls. This study demonstrated that the cortical development of individuals with ADHD happens later than in healthy children. Furthermore, the sequence of development is similar in cases and controls (primary sensory and motor areas reaching its peak before hierarchically higher association areas), suggesting a delay rather than a shift in cortical maturation in the neurobiology of ADHD. Interestingly, the only region of earlier maturation in relation to the control group is the primary motor cortex of patients with ADHD. According to the authors, the early maturation of this region associated with a delayed maturation of superior motor areas may be responsible for excessive and poorly controlled motor activity in ADHD individuals.

In a study involving adults, Makris et al. ${ }^{37}$ compared the cortical thickness of 24 patients with ADHD with that of 14 normal individuals, observing the reduction in areas related to the attentional circuit: right inferior parietal lobe, prefrontal cortex and bilateral anterior cingulate gyrus bilaterally. Altered functioning of the right inferior parietal lobe, in the angular gyrus, is associated with loss of spatial attention and language deficits, whereas thinning of the prefrontal cortex is associated with deficits in organization, planning, working memory and other executive dysfunctions, which are observed in patients with ADHD, even in adulthood. Abnormalities in the cingulate gyrus are associated with, among others, the deficit in decision-making based on reward that is observed in individuals with $\mathrm{ADHD}^{38}$.

\section{Spectroscopy}

Spectroscopy is a MR method that allows detection of metabolites such as $\mathrm{N}$-acetyl-aspartate (NAA), creatine $(\mathrm{Cr})$, choline compounds (Cho), glutamate (Glu), myoinositol (Mio) and gamma- amino butyric acid (GABA) in the central nervous system in a non-invasive way ${ }^{39}$.

NAA is a neuronal marker, since it is present only in axons and dendrites. It is synthesized in the mitochondria and its concentration is directly related to the consumption of oxygen and the synthesis of myelin. NAA reductions occur in states such as loss of neurons and dendrites, and reduced myelination and neuronal metabolism. The peaks of choline are associated with the synthesis and breakdown of cell membranes, representing a marker of cell membrane turnover. Creatine has an un- 
clear role in neurology, but reductions in its concentration tend to be associated with states of decreased cerebral metabolism. Since many MRI studies assume that its concentration is relatively constant in the brain, its values are references to measures of other metabolites Lactate is seldom detected in healthy brain. The elevations of this metabolite are associated with the oxidative metabolism that occurs in conditions such as hypoxia. Myo-inositol is found in large quantities in glial cells, plays an important role in osmoregulation and neurotransmission and rises in cases of gliosis. Finally, glutamate is an excitatory neurotransmitter involved in motor and cognitive functions, being a marker of neuronal activity ${ }^{40}$.

There are theories about the neurobiology of ADHD involving both the pathways which use dopamine as a neurotransmitter and those that use glutamate. In accordance with Sagvolden et al. ${ }^{41}$, in ADHD patients, we observed a failure of transmission in pathways that use glutamate as a response to a deficit of dopaminergic pathways. Thus, hypofunction in meso-limbic dopaminergic pathways would lead to symptoms such as hyperactivity, impulsivity, attention deficit and disinhibition, whereas hypofunction in the meso-cortical pathways provides executive dysfunction. In this sense, the levels of glutamate in the prefrontal regions and limbic would be a good marker of dopaminergic dysfunction in ADHD patients.

Exploring the pathways modulated by glutamate in patients with ADHD, Perlov et al. ${ }^{42}$ used spectroscopy to investigate 28 adult patients and compared the results to those of an equal number of controls. They observed that individuals with ADHD showed lower levels of Glu/ $\mathrm{Cr}$ ratio in the anterior cingulate cortex, supporting the hypothesis of dysfunction of the dopaminergic pathways of the meso-limbic circuit, which is involved in the neurobiology of ADHD.

In view of previous studies that showed increases in the NAA/Cr ratio in the frontal region and the left semioval center ${ }^{43}$, Fayed et al. ${ }^{44}$ explored these same areas through spectroscopy and diffusion in ADHD patients and controls. A comparison of 22 ADHD individuals of both sexes with and without treatment and 8 controls showed no differences in apparent diffusion coefficient between groups but found an increase in the NAA/Cr ratio in the right prefrontal regions and the left semioval center in ADHD patients. In this study, the authors admit that diffusion MR is not the most appropriate method for detecting abnormalities of white matter, but DTI. However, this technique was not available to the authors at the time of the study. As for the metabolic abnormalities detected, the authors suggest that an increase in mitochondrial metabolism would be responsible for increasing the NAA/Cr ratio in the studied regions and is related to a state of excess catecholamines.
In 2003, MacMaster et al. ${ }^{45}$, studying spectroscopy in a small group of patients with ADHD, showed increased levels of glutamate and glutamine in frontostriatal circuits in those patients, but no changes were noted in rates of NAA, $\mathrm{Cr}$ and Cho. This observation supports the hypothesis of dysfunction in the frontal circuits involved in the neurobiology of ADHD.

Sun et al. ${ }^{46}$ tried to explore the difference between the spectroscopy of inattentive and combined ADHD subtypes, given that the first group has several neuropsychological differences from other subtypes. In this study, they observed reduction of NAA/Cr ratio bilaterally in the lenticular nuclei in patients with ADHD combined subtype, but no difference was observed among patients with ADHD inattentive subtype and the control group. Comparing combined and inattentive subtypes, the former shows greater reduction in NAA/Cr ratio in the right lenticular nucleus when compared to the latter. On the left side, the difference was not statistically significant. These results are consistent with previous studies that showed clinical and neurophysiological differences between the two subtypes.

Recently, there emerged a more advanced MR technique called near-infrared spectroscopy (NIRS), which consists of non-invasive method to measure changes in concentration of oxy and deoxy-hemoglobin in brain tissue $^{47}$. It has advantages for the functional study of the brain in relation to fMRI such as the possibility that the patient remain seated while performing the neuropsychological assessment and less susceptibility to motion $\operatorname{artifacts}^{48}$.

According Ehlis et al. ${ }^{48}$, functional studies of patients with ADHD showed some inconsistencies concerning the function of the frontal lobe. In this sense, these authors conducted a study involving use of NIRS in 13 adults with ADHD of both sexes and an equal number of controls during performance of neuropsychological test for assessing working memory. It was observed that individuals with ADHD had lower oxygen uptake in ventrolateral prefrontal cortex during the execution of the tests, meaning a lower activation in this region in these patients. Using the same technique in a recent study, Negoro et al. ${ }^{49}$ also observed reductions in oxygen uptake in the region of inferior prefrontal cortex bilaterally in ADHD patients during performance of executive function tests.

\section{Correlation of brain morphometry and DTI with functional MRI data in patients with ADHD}

According to Rubia et al. ${ }^{24}$, functional magnetic resonance imaging (fMRI) is a noninvasive technique that allows the study of the activation of well defined areas of the brain with good spatial resolution and during the 
performance of cognitive tasks. During the task, images are acquired using a contrast method for measuring the oxygen consumption by different regions of the brain called BOLD: blood-oxygenation-level-dependent $t^{50}$. According to Bush et al. ${ }^{51}$, functional brain images are useful for studies on neurobiology, effects of drug treatment and diagnostic tests. In this regard, neuroimaging studies involving functional magnetic resonance imaging complement and assist in understanding the findings of tests involving DTI and morphometry.

Based on the premise that patients with ADHD have poor control of inhibition of motor responses and studies showing a correlation between volume reduction in frontal/striatal and low performance on tests of response inhibition, Rubia et al. ${ }^{52}$ investigated brain activation in patients with ADHD using fMRI. In this study, seven adolescents with ADHD had their motor performance on standardized tests of response inhibition and synchronization of motor response compared to nine adolescents without the disorder. It was observed that patients with ADHD had lower brain activity, especially in the mesial frontal cortex of the right hemisphere during both tests and in the prefrontal cortex and the right lower left caudate during the inhibition test, a condition that the authors described as hypofrontality.

Recent fMRI studies have brought new hypotheses for the neurobiology of ADHD. According to Mohanty et al. ${ }^{53}$, brain reward systems are capable of causing an upregulation on the system that mediates the selective attention, such as the prefrontal cortex, parietal and posterior cingulate gyrus. In this sense, Rubia et al. ${ }^{54}$ published a study aiming to understand the effect of methylphenidate on the regions associated with executive functions of attention and inhibition of behavior - fronto-striatal and fronto-parietal network - and the regions related to motivation - orbitofrontal cortex and limbic structures. In this study, 13 adolescents with ADHD, with and without treatment with methylphenidate, and an equal number of healthy individuals of similar age performed a study of using BOLD fMRI technique while performing neuropsychological testing that measured vigilant selective attention and the effects of reward. It was observed that untreated ADHD patients have reduced activation in fronto-striato parieto-cerebellar network bilaterally during tests of attention, but show increased activation in the orbitofrontal cortex and superior temporal, rewardrelated. The use of methylphenidate, however, increases the activation of fronto-striato parieto-cerebellar regions and normalizes the function of the orbitofrontal region.

Durston et al. ${ }^{55}$ used a motor inhibition task and found that children between 6 and 10 years old with ADHD do not activate the fronto-striatal area in the same way that children of same level of development without the disorder. ADHD patients make use of a more diffuse network of brain areas including more posterior and dorsolateral prefrontal regions. These findings are consistent with delayed maturation of the fronto-striatal circuit. Taking into account the results of previous studies that corroborated the hypothesis of deficits of executive function and selective attention and inhibitory control, Tamm et al. ${ }^{56}$ performed fMRI study comparing performance on tests of motor inhibition of ten adolescents with ADHD and twelve healthy subjects. It was observed that ADHD subjects had abnormalities in brain activation during motor response inhibition, including low activation of anterior and middle cingulate extending to the supplementary motor area. Abnormalities in cingulate have already been described in DTI studies ${ }^{57}$.

Abnormalities of the striatum have also been described in many fMRI studies ${ }^{46}$. Vaidya et al. ${ }^{58}$ demonstrated the presence of frontal and striatal abnormalities on tests of executive function in patients with ADHD, while Rubia et al. ${ }^{24}$ observed lower response in the right mesial prefrontal cortex, the right inferior prefrontal cortex and left caudate nucleus, the latter finding being similar to that of Durston et al..$^{55}$.

As for the lateral frontal cortex, there is little consensus on functional studies. Although Rubia et al. ${ }^{24}$ have demonstrated deficit in this area on executive function tests, no significant difference in lateral frontal cortex activation in patients and non-ADHD patients were seen in the study by Durston et al. ${ }^{55}$.

DTI was used by Casey et al. ${ }^{59}$ in a functional study to assess how variation in the fronto-striatal white matter tracts might contribute to deficits in executive function (especially the lack of control of inhibition) in ADHD individuals. In this study, it was observed a correlation between lower FA in the fronto-striatal regions (prefrontal cortex and caudate nucleus) and poorer cognitive performance on tests of inhibition. Moreover, there was an association between ADHD patients and their parents in FA in frontostriatal right fibers, reinforcing the idea of heritability of frontostriatal structures right in with ADHD. This finding reinforces the idea of an atypical development of frontostriatal tracts causing cognitive impairment. According to Sowell et al. ${ }^{60}$, it is known that the white matter of the prefrontal region matures more slowly during childhood and adolescence. Thus, together with the data from this study, we can state that increased cognitive control corresponds to a progressive myelination of frontostriatal regions.

\section{CONCLUSIONS}

MRI advanced techniques involving DTI, spectroscopy and morphometry has brought great advances in the understanding of the neurobiology of ADHD. Al- 
though there are still some inconsistencies between studies, the results obtained so far demonstrate the potential involvement of the splenium of corpus callosum, cingulated gyrus, caudate nucleus, cerebellum, striatum, frontal and temporal cortices in the genesis of this disorder. In order to make the findings more robust, studies are needed involving a larger number of subjects in prospective way.

It is noteworthy that, although promising, the techniques described above have not yet been incorporated in daily clinical practice and, in patients with ADHD, they are used primarily in clinical research. It is also important to note that differences can be observed when analyzing groups of individuals with ADHD and control subjects, but it is difficult to distinguish differences in individual cases.

\section{REFERENCES}

1. American Psychiatric Association. Diagnostic and statistical manual of mental disorders. $4^{\text {th }}$ Ed. (DSM-IV). Washington, DC: American Psychiatric Association, 1994.

2. Polanczyk G, De Lima MS, Horta BL, Biederman J, Rohde LA. The world wide prevalence of ADHD: a systematic review and metaregression analysis. Am J Psychiatry 2007;164:942-948.

3. Castellanos FX, Lee PP, Sharp W, et al. Developmental trajectories of brain volume abnormalities in children and adolescents with attention-deficit/ hyperactivity disorder. JAMA 2002;288:1740-1748.

4. Ashtari M, Kumra S, Bhaskar SL, et al. Attention-deficit/hyperactivity disorder: a preliminary diffusion tensor imaging study. Biol Psychiatry 2005; 57:448-455.

5. Le Bihan D. Looking into the functional architecture of the brain with diffusion MRI. Nat Rev Neurosci 2003;4:469-480.

6. Mori S, Zhang J. Principles of diffusion tensor primer imaging and its applications to basic neuroscience research. Neuron 2006;51:527-539.

7. Silk TJ, Vance A, Rinehart N, Bradshaw JL, Cunnington R. White-matter abnormalities in attention deficit hyperactivity disorder: a diffusion tensor imaging study. Hum Brain Mapp 2009;30:2757-2765.

8. Conturo TE, Lori NF, Cull TS, et al. Tracking neuronal fiber pathways in the living human brain. Proc Natl Acad Sci USA 1999;96:10422-10427.

9. Smith SM, Jenkinson M, Johansen-Berg H, et al. Tract-based spatial statistics: voxelwise analysis of multi-subject diffusion data. Neuroimage 2006; 31:1487-1505

10. Ashtari M, Cervellione KL, Hasan KM, et al. White matter development during late adolescence in healthy males: a cross-sectional diffusion tensor imaging study. Neuroimage 2007;35:501-510.

11. El-Sayed E, Larsson JO, Persson HE, Santosh PJ, Rydelius PA. "Maturational lag" hypothesis of attention deficit hyperactivity disorder: an update. Acta Paediatr 2003;92:776-784

12. Amador N, Fried I. Single-neuron activity in the human supplementary motor area underlying preparation for action. J Neurosurg 2004;100: 250-259.

13. Levisohn L, Cornin-Golomb A, Schmahmann JD. Neuropsychological consequences of cerebellar tumour resection in children: cerebellar cognitive affective syndrome in a paediatric population. Brain 2000;123:1041-1450.

14. Silk TJ, Vance A, Rinehart N, Bradshaw JL, Cunnington R. Structural development of the basal ganglia in attention deficit hyperactivity disorder: a diffusion tensor imaging study. Psychiatry Res 2009;172:220-225.

15. Pavuluri MN, Yang S, Kamineni K, et al. Diffusion tensor imaging study of white matter fiber tracts in pediatric bipolar disorder and attention-deficit/hyperactivity disorder. Biol Psychiatry 2009;65:586-693.

16. Semrud-Clikeman MS, Filipek PA, Biederman J, et al. Attention-defici hyperactivity disorder: magnetic resonance imaging morphometric analysis of the corpus callosum. J Am Acad Child Adolesc Psychiatry 1994;33: 875-881.

17. Valera EM, Faraone SV, Murray KE, Seldman LJ. Meta-analysis of structural imaging findings in attention-deficit/hyperactivity disorder. Biol Psychiatry 2007;61:1361-1369.

18. Baumeister AA, Hawkins MF. Incoherence of neuroimaging studies of attention deficit/hyperactivity disorder. Clin Neuropharmacol 2001;24:2-10.

19. Krishnan KRR, Doraiswamy PM. Brain imaging in clinical psychiatry. New York: Marcel Dekker, 1997.

20. Giedd JN, Castellanos FX, Casey BJ et al. Quantitative morphology of the corpus callosum in attention deficit hyperactivity disorder. Am J Psychiatry 1994;151:665-669.

21. Mataró M, Garcia-Sánchez C, Junqué C, Estévez-González A, Pujol J. Magnetic resonance imaging measurement of the caudate nucleus in adolescents with attention-deficit hyperactivity disorder and its relationship with neuropsychological and behavioral measures. Arch Neurol 1997:54: 963-968.

22. Hynd GW, Hern KL, Novey ES, et al. Attention deficit-hyperactivity disorder and asymmetry of the caudate nucleus. J Child Neurol 1993;8:339-347.

23. Seidman LJ, Valera EM, Makris N. Structural brain imaging of attentiondeficit/hyperactivity disorder. Biol Psychiatry 2005;57:1263-1272.

24. Rubia K, Overmeyer S, Taylor E, et al. Hypofrontality in attention deficit hyperactivity disorder during higher-order motor control: a study with functional MRI. Am J Psychiatry 1999;156:891-896

25. Carmona S, Vilarroya, Bielsa A. Global and regional gray matter reductions in ADHD: a voxel-based morphometric study. Neurosci Lett 2005;389:88-93.

26. Abernethy LJ, Palaniappan M, Cooke RW. Quantitative magnetic resonance imaging of the brain in survivors of very low birth weight. Arch Dis Child 2002;87:279-283.

27. Filipek PA, Semrud-Clikeman M, Steingard RJ, Renshaw PF, Kennedy DN, Biederman J. Volumetric MRI analysis comparing subjects having attention-deficit hyperactivity disorder and normal controls. Neurology 1997; 48:589-601.

28. Mostofsky SH, Cooper KL, Kates WR, Denckla MB, Kaufmann WE. Smaller prefrontal and premotor volumes in boys with attention-deficit/hyperactivity disorder. Biol Psychiatry 2002;52:785-794.

29. Castellanos FX, Tannock R. Neuroscience of attention-deficit/hyperactivity disorder: the search for endophenotypes. Nat Rev Neurosci 2002;3: 617-628.

30. Mackie S, Shaw P, Lenroot R, et al. Cerebellar development and clinical outcome in attention deficit hyperactivity disorder. Am J Psychiatry 2007; 164:647-655.

31. Fischl B, Sereno MI, Dale AM. Cortical surface-based analysis. II: inflation, flattening, and a surfacebased coordinate system. Neuroimage 1999;9: 195-207.

32. Tamnes CK, Ostby Y, Fjell AM, Westlye LT, Due-Tonnessen P, Walhovd KB. Brain maturation in adolescence and young adulthood: regional age-related changes in cortical thickness and white matter volume and microstructure. Cereb Cortex 2010;20:534-548.

33. Shaw P, Kabani NJ, Lerch JP, et al. Neurodevelopmental trajectories of the human cerebral cortex. J Neurosci 2008;28:3586-3594.

34. Ostby Y, Tamnes CK, Fjell AM, Westlye LT, Due-Tonnessen P, Walhovd KB. Heterogeneity in subcortical brain development: a structural magnetic resonance imaging study of brain maturation from 8 to 30 years. J Neurosci 2009;29:11772-11782.

35. Dickstein SG, Bannon K, Castellanos FX, Milham MP. The neural correlates of attention deficit hyperactivity disorder: an ALE meta-analysis. J Child Psychol Psychiatry 2006;47:1051-1062.

36. Shaw P, Eckstrand K, Sharp W, et al. Attention-deficit/hyperactivity disorder is characterized by a delay in cortical maturation. Proc Natl Acad Sci USA 2007;104:19649-19654.

37. Makris N, Biederman J, Valera EM, et al. Cortical thinning of the attention and executive function networks in adults with attention-deficit/hyperactivity disorder Cereb Cortex 2007;17:1364-1375

38. Bush G, Vogt BA, Holmes J, et al. Dorsal anterior cingulate cortex: a role in reward-based decision making. Proc Natl Acad Sci USA 2002;99:523-528.

39. Ross B, Bluml S. Magnetic resonance spectroscopy of the human brain. Anat Rec 2001:265:54-84.

40. Minati L, Grisoli M, Bruzzone MG. MR spectroscopy, functional MRI, and diffusion-tensor imaging in the aging brain: a conceptual review. J Geriatr Psychiatry Neurol 2007;20:3-21

41. Sagvolden $T$, Johansen EB, Aase $H$, Russell VA. A dynamic developmental theory of attention-deficit/hyperactivity disorder (ADHD) predominantly hyperactive/impulsive and combined subtypes. Behav Brain Sci 2005;28: 397-419.

42. Perlov E, Philipsen A, Hesslinger B, et al. Reduced cingulate glutamate/ glutamine-to-creatine ratios in adult patients with attention deficit/hy- 
peractivity disorder: a magnet resonance spectroscopy study. J Psychiatr Res 2007:41:934-941.

43. Fayed N, Modrego PJ. Comparative study of the cerebral white matter in autism and attention-deficit/hyperactivity disorder by means of magnetic resonance spectroscopy. Acad Radiol 2005;12:566-569.

44. Fayed N, Modrego PJ, Castillo J, Dávila J. Evidence of brain dysfunction in attention deficit-hyperactivity disorder: a controlled study with proton magnetic resonance spectroscopy. Acad Radiol 2007;14:1029-1035.

45. MacMaster FP, Carrey N, Sparkes S, Kusumakar V. Proton spectroscopy in medication-free pediatric attention-deficit/hyperactivity disorder. Biol Psychiatr 2003;53:184-187

46. Sun L, Jin Z, Zang Y. Differences between attention-deficit disorder with and without hyperactivity: a $1 \mathrm{H}$-magnetic resonance spectroscopy study. Brain Dev 2005;27:340-344.

47. Watanabe A, Kato T. Cerebrovascular response to cognitive tasks in patients with schizophrenia measured by near-infrared spectroscopy. Schizophr Bull 2004;30:435-444.

48. Ehlis AC, Bähne CG, Jacob CP, Herrmann MJ, Fallgatter AJ. Reduced lateral prefrontal activation in adult patients with attention-deficit/hyperactivity disorder (ADHD) during a working memory task: a functional nearinfrared spectroscopy (fNIRS) study. J Psychiatr Res 2008;42:1060-1067.

49. Negoro H, Sawada M, lida J, Ota T, Tanaka S, Kishimoto T. Prefrontal dysfunction in attention-deficit/hyperactivity disorder as measured by nearinfrared spectroscopy. Child Psychiatry Hum Dev 2010;41:193-203.

50. Ogawa S, Lee TM, Kay AR, Tank DW. Brain magnetic resonance imaging with contrast dependent on blood oxygenation. Proc Natl Acad Sci USA 1990;3:9868-9872.

51. Bush G, Valera EM, Seidman LJ. Functional neuroimaging of attentiondeficit/hyperactivity disorder: a review and suggested future directions. Biol Psychiatry 2005;57:1273-1284.
52. Rubia K, Smith AB, Brammer MJ, Toone B, Taylor E. Abnormal brain activation during inhibition and error detection in medicationnaive adolescents with ADHD. Am J Psychiatry 2005;162:1067-1075.

53. Mohanty A, Gitelman DR, Small DM, Mesulam MM. The spatial attention network Interacts with limbic and Monoaminergic systems to modulate motivation-induced attention shifts. Cerebral Cortex 2008;18: 2604-2613.

54. Rubia K, Halari R, Cubillo A, Mohammad AM, Brammer M, Taylor E. Methylphenidate normalises activation and functional connectivity deficits in attention and motivation networks in medication-naïve children with ADHD during a rewarded continuous performance task. Neuropharmacology 2009;57:640-652.

55. Durston S, Tottenham NT, Thomas KM, et al. Differential patterns of striatal activation in young children with and without ADHD. Biol Psychiatry 2003;53:871-878.

56. Tamm L, Menon V, Ringel J, Reiss AL. Event-related FMRI evidence of frontotemporal involvement in aberrant response inhibition and task switching in attention-deficit/hyperactivity disorder. J Am Acad Child Adolesc Psychiatry 2004;43:1430-1440.

57. Hamilton LS, Levitt JG, O'Neill J, et al. Reduced white matter integrity in attention-deficit hyperactivity disorder. Neuroreport 2008;19:1705-1708.

58. Vaidya CJ, Austin G, Kirkorian G, et al. Selective effects of methylphenidate in attention deficit hyperactivity disorder: a functional magnetic resonance study. Proc Natl Acad Sci USA 1998;95:14494-14499.

59. Casey BJ, Epstein JN, Buhle J, et al. Frontostriatal connectivity and its role in cognitive control in parent-child dyads with ADHD. Am J Psychiatry 2007;164:1729-1736.

60. Sowell ER, Thompson PM, Holmes CJ, Batth R, Jernigan TL, Toga AW. In vivo evidence for post-adolescent brain maturation in frontal and striatal regions. Nat Neurosci 1999;2:859-861. 